\title{
THE IMPACT OF CONGESTION MANAGEMENT ON AIR POLLUTION EMISSIONS IN URBAN FREEWAYS
}

\author{
P. KOPELIAS ${ }^{1}$, K. VOGIATZIS ${ }^{2} \&$ A. SKABARDONIS ${ }^{3}$ \\ ${ }^{1}$ Lecturer, University of Thessaly, Department of Civil Engineering, Greece. \\ ${ }^{2}$ Ass. Professor, University of Thessaly, Department of Civil Engineering, Greece. \\ ${ }^{3}$ Professor, University of California, Department of Civil \& Environmental Engineering, Berkeley.
}

\begin{abstract}
Urban and semi urban transport contributes considerably to many environmental problems, e.g. air pollution and environmental noise. Congestion in motorways in particular, has a significant effect in traffic conditions and the atmospheric environment as well. In addition to delays and queues incidents also affect fuel consumption and air pollution. Athens Ring Tollway ("Attiki Odos" or "Attika Tollway" - "AT") is a 70 km freeway centreline length in each direction and is used as a Ring Road for Athens, the capital of Greece. The harmonious co-existence of the motorway with the environment has been a difficult task, but successfully achieved by Attica Tollway regarding environmental noise through the implementation of comprehensive management, including monitoring, assessment \& implementation of the appropriate mitigation measures i.e. noise barriers $\&$ land use organization. In this article and in order to further calculate and evaluate the benefits of AT incident management which is given through Attica Tollway Patrol Service (ATPS), Freeway Service Patrol Evaluation Methodology (FSPE) is used. An FSPE model has been examined for the effect of ATSP in the total length of the freeway for the year 2009.

Keywords: Air pollution, Attiki Odos, fuel consumption, incident management, traffic congestion, urban freeways.
\end{abstract}

\section{INTRODUCTION}

Congestion in motorways has significant effect in traffic conditions and the atmospheric environment as well. According to the Federal Highway Administration [1], road incidents with impact on traffic capacity in USA is the second cause of congestion following the effect of 'physical bottlenecks' (lane drop, merging areas, ramps, etc). FHWA also indicates [2], that $60 \%$ of the delays are due to incidents in urban motorways. Other studies [3,4] showed that incidents cause more than $50 \%$ of total delays experienced by motorists in all urban areas. Half of that $(25 \%)$ is caused by traffic incidents such as crashes, breakdowns, road debris and spilled cargo. It is also reported [5] that the congestion "invoice" for the cost of extra time and fuel in 439 urban areas in the US (all values in constant 2010 dollars) was $\$ 101$ billion in 2010 in comparison with $\$ 79$ billion in 2000 and $\$ 21$ billion in 1982. In addition to delays and queues incidents also affect fuel consumption and air pollution. A stochastic model by Salimol and Jacko [6] estimates the average emission of CO, VOC, $\mathrm{NO}_{\mathrm{X}}$, and $\mathrm{PM}_{2.5}$, and traffic delays due to incidents. The study indicates that a $5 \%$ reduction in traffic via rerouting or other demand management can reduce emissions up to $30 \%$.

One of the most important actions to relief congestion, compared with other measures such as pricing, high occupancy lanes, etc is Traffic Incident Management (TIM).TIM consists of a planned and coordinated multi-disciplinary process to detect, respond and clear traffic incidents so that traffic flow may be restored as safely and quickly as possible [7]. Effective TIM reduces the duration and the impacts of traffic incidents and improves the safety of motorists, crash victims and emergency responders [8]. In freeways, an essential component of TIM, is Patrol or Intervention Teams which are small trucks or vans patrolling along the freeway and are usually dispatched by Traffic Control Centres operators to intervene to an incident. Studies in the USA indicated that the percentage of covered motorways by Patrol Services in 2008 was $46 \%$ of the total motorway network [7]. 
Urban and semi urban transport contributes considerably to many environmental problems, e.g. air pollution and environmental noise. According to European Commission's statistics, in the year 2000 , the transport sector contributed $29 \%$ of all $\mathrm{CO}_{2}$ emissions in the $\mathrm{EU}$, of which road transport was responsible for $83 \%$. Traffic congestion, in particular, is responsible for major environmental and economic impacts and building new transport infrastructure is unlikely to give a reliable solution towards a sustainable transport and mobility [9].

In order to evaluate the environmental impact, in terms of air pollutant emissions, it is necessary to evaluate the real driving patterns reflecting different types of road network, the traffic conditions with emphasis to congestion events and drivers' behaviour characteristics [10].

Athens Ring Tollway ("Attiki Odos" or "Attika Tollway" - "AT"), is a $70 \mathrm{~km}$ freeway centreline length in each direction and is used as a Ring Road for Athens, the capital of Greece. There are 39 entrances to the rollway through toll plazas with 195 toll lanes. Mainly it is a 3 lane freeway with a small section (less than $20 \mathrm{~km}$ ) with 2 lanes.

AT was delivered in segments starting May of 2001 and was concluded in late spring of 2004, prior to the 2004 summer Olympics. It consists of two major freeway sections, which are perpendicular to one another: a) The "Elefsina - Stavros - Spata A/O (ESSM - AO), b) The "Imittos Western Peripheral Motorway" (IWPM). The Attika Tollway network is equipped with 8 air pollution monitoring stations in selected locations (Fig. 1)

\section{ATMOSPHERIC POLLUTION MONITORING IN ATTICA TOLLWAY}

The harmonious co-existence of the motorway with the environment has been a difficult task, but successfully achieved by Attica Tollway regarding environmental noise through the implementation of comprehensive management, including monitoring, assessment \& implementation of the appropriate mitigation measures i.e. noise barriers \& land use organization.

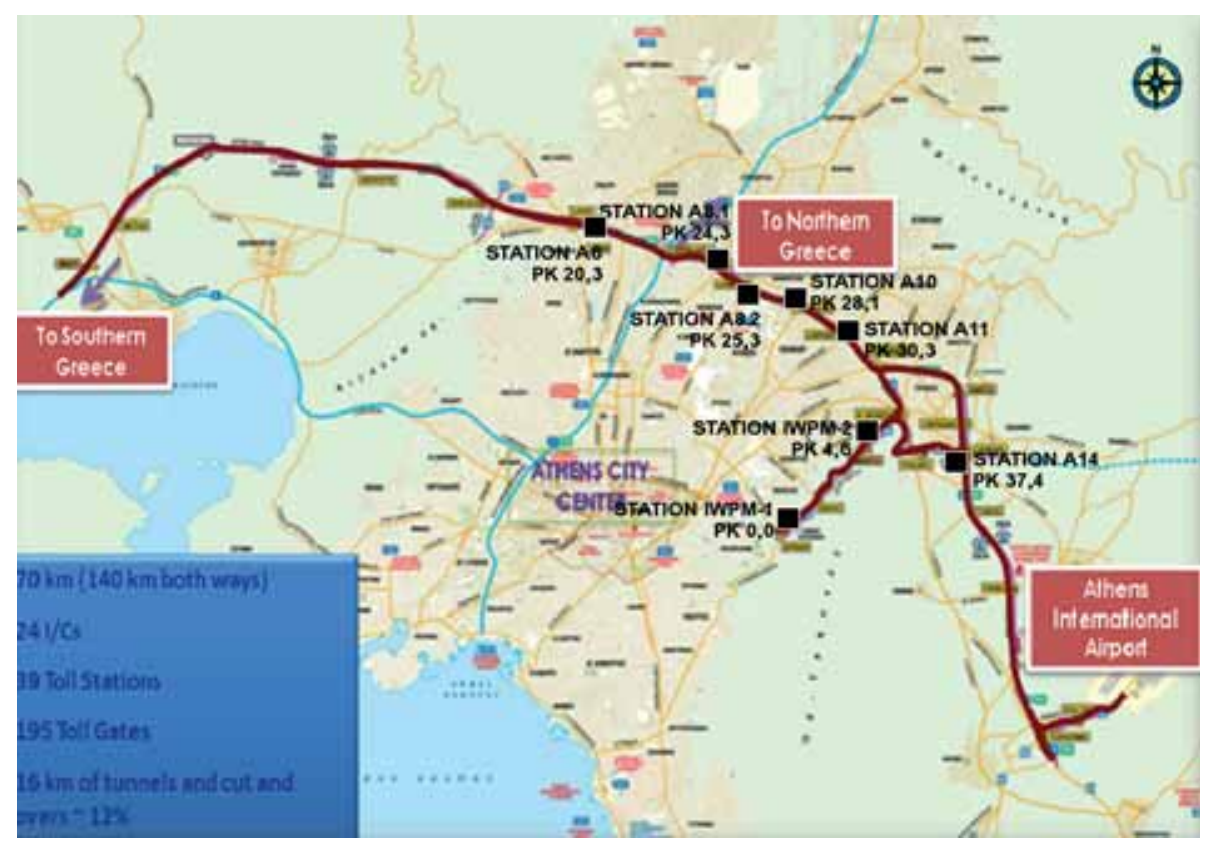

Figure 1: Attica tollway network layout: air pollution monitoring stations. 
Within the framework of environmental monitoring regarding impacts due to AT's operations, an integrated network of 8 permanent and fully automatic monitoring stations, including environmental road traffic noise, atmospheric pollution and meteorological data monitoring equipment, has been installed and is operating successfully [11].

In order for AT to conform to the European directive 2008/50/EC [12] before the given deadline (1/1/2009), as well as to complete the upgrade - completion of the system's adaptation to the European directive 2002/49/EC [13], AT network proceeded: (a), in the execution of a transitional - short period - monitoring program regarding suspended particles $\left(\mathrm{PM}_{10} \& \mathrm{PM}_{2.5}\right)$, in order to evaluate the need of continuous monitoring as well as the physical relation between them, (b) after completion of this program the installation of $\mathrm{PM}_{2,5}$ \& BTEX sensors, and, (c) to the complete upgrade of the existing permanent stations of monitoring environmental road traffic noise with integrated self-recording systems and a telematic system via fibre optics.

Therefore the new fully operating updated network ensures, the continuous recording of $\mathrm{PM}_{2,5}$ the continuous recording and monitoring of concentration of benzene and finally the complete upgrade and adaptation of "real time" acoustic recordings of the Road Traffic Noise indices as per the EU directive 2002/49/EC and the relative existing Greek legal framework (JMD 13586/724/ FEK/B/384/28/3/2006) [13], within a full communication telematics network based of optical fibres.

From, the total of 8 monitoring stations especially in the stations referred as A8.2 \& IWPM 2 (see Fig. 1) a full monitoring equipment version is installed including $\mathrm{CO}, \mathrm{NO}_{2}, \mathrm{PM}_{10}, \mathrm{PM}_{2,5}$ \& $\mathrm{BTEX}$ sensors, it is interesting to present (see Figs 2 and 3), the relevant comparative fluctuation of the above air pollutants (all in $\mu \mathrm{g} / \mathrm{m} 3$ except $\mathrm{CO}$ in $\mathrm{mg} / \mathrm{m} 3$ ) for an 18 months time period (2010-2011).

The comparative average traffic flow fluctuation is also presented in the following Fig. 4. On both monitoring stations the average values of all pollutants present a steady consistence and correlation with the average road traffic flows, even though in some cases, important variations on both average speed and local climatic conditions, especially in different seasonal periods, may affect the results.

The correlation of the above long term measured data (traffic flow and air pollutants) justify that consistent efforts of AT operations authority related to congestion management which should bring significant results in air pollution abatement. In addition to traffic measures such as traffic information

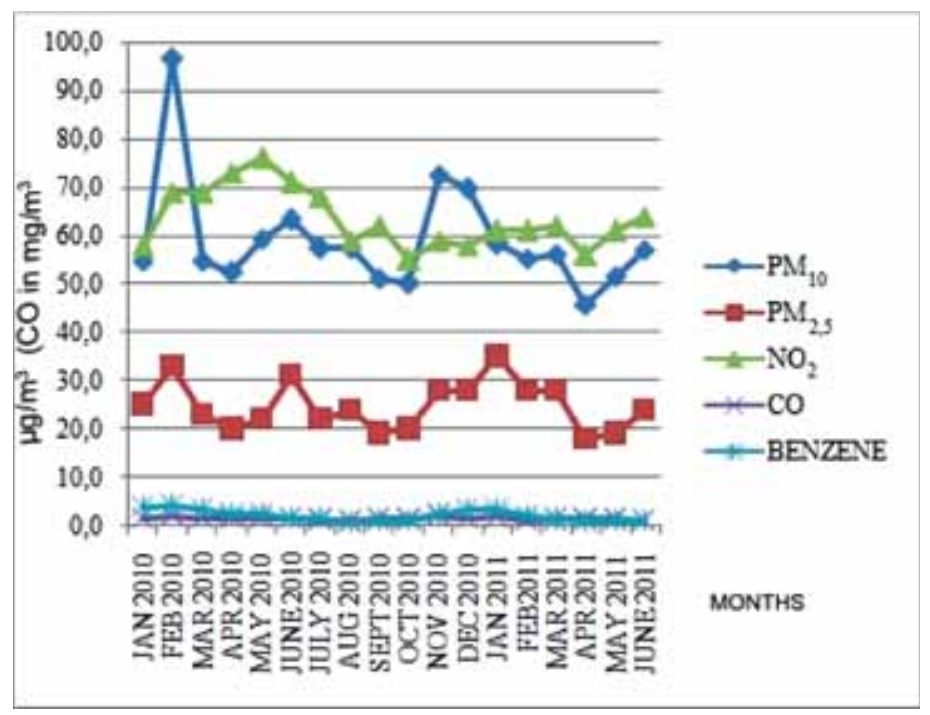

Figure 2: Station A 8.2 - all air pollutants. 


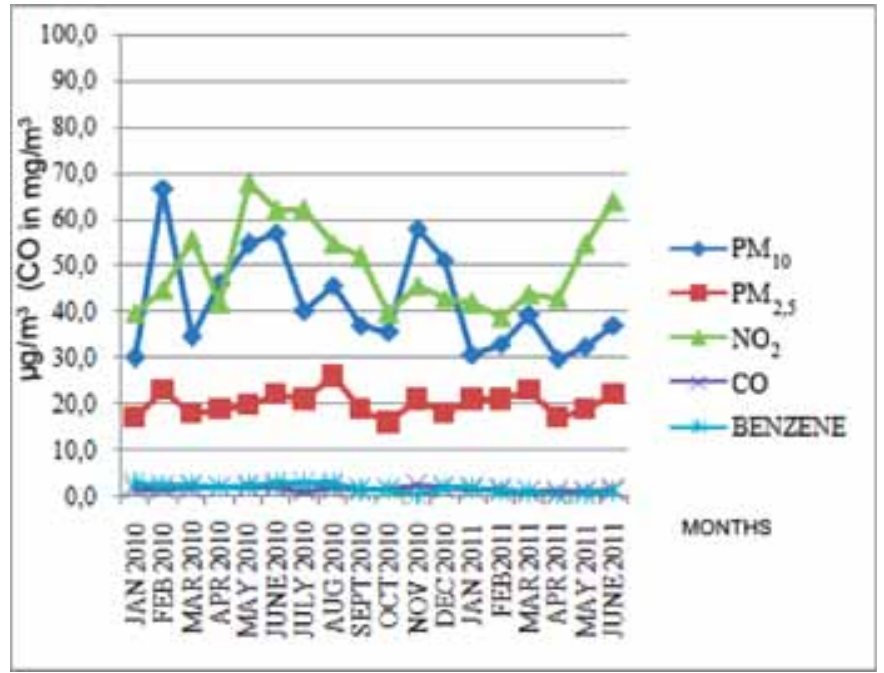

Figure 3: Station IWPM 2 - all air pollutants.

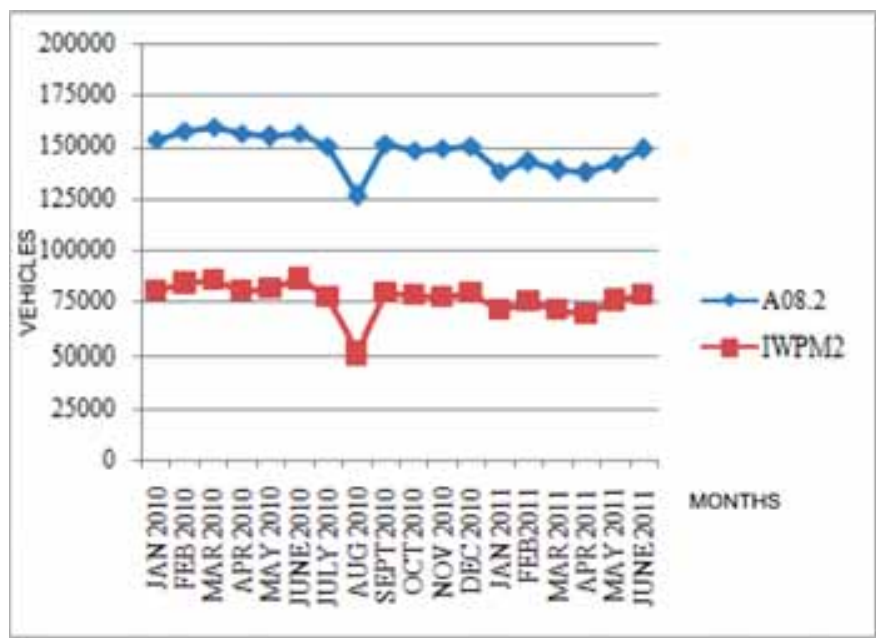

Figure 4: Monthly average fluctuation of daily road traffic flows at both monitoring stations.

to the users, variable speed limits, real time traffic management, etc, traffic incident management seems to be a critical positive factor for the reduction of the non-recurrent congestions impacts both in road traffic and the atmospheric environment.

In this article and in order to further calculate and evaluate the benefits of AT incident management which is given through Attica Tollway Patrol Service (ATPS), Freeway Service Patrol Evaluation Methodology (FSPE) is used. The FSPE model evaluation considers the benefit resulting from the reduction of delays, fuel consumption and emissions comparing "with" and "without" ATPS features and effects of an incident (duration, lane/s closure, capacity reduction, delays, average speed in queue, etc). The final result is the $\mathrm{B} / \mathrm{C}$ ratio (Benefit/Cost ratio i.e. the total benefit (B) for the users due to fuel and time savings over the total operational cost $(\mathrm{C})$ of the patrol service scheme). 


\section{TRAFFIC AND CONGESTION FEATURES IN ATTICA TOLLWAY}

Traffic demand in AT was growing until 2009 when the average number of daily vehicle entries through the toll plazas was about 307.000 vehicles. From 2010 a significant reduction took place, mainly due to economic crisis in Greece, and the average number of daily entries dropped to 250.000 in 2011 ( $-19,5 \%$ compared to 2009).

Traffic relevant characteristics of AT operation from 2005 to 2011 are presented in Fig. 5 hereafter.

The most heavily-trafficked section of AT is the $10 \mathrm{~km}$ central urban section with an average daily traffic of about 85.000 vehicles per direction during working days in 2009 (the year with peak traffic in the motorway) and 75.000 vehicles per direction during working days in 2011.

A typical working day peak hour volume, in this 3-lane mainline segment, is approximately 6.500 $\mathrm{veh} / \mathrm{hr} / \mathrm{dir}$, while during the days corresponding to peak daily number of entries peak hour volume exceeds the $6.500 \mathrm{veh} / \mathrm{h}$.

Traffic's peak hour volume of about 6.500 vehicles is close to the theoretical capacity of the 3-lane mainline section [14], contributing to the reduction of the level of service and resulting in the increase of delays and the lengthening of queues for a certain period of the day. Also, in case of any incidents in this section during peak hours, it is obvious that queues are faster and longer spread even though the response time of Patrols is very low (5 minutes in average from 2005 to 2011).

The following Fig. 6 shows a significant reduction of the average speed during the working days of July of 2009 (one of the most heavily-trafficked period on record), in comparison with the same month's working days (not congested conditions under usual circumstances) on the central section of the motorway.

The reduction observed during the morning peak hours, is about $36 \%$ compared to the Sunday speeds ( $63 \mathrm{~km} / \mathrm{h}$ on working days vs $98 \mathrm{~km} / \mathrm{h}$ on Sundays).

Number of incidents recorded by AT Traffic Management Centre follows the pattern of Annual Average Daily Entries (AADE: Annual Average Daily Entries). Table 1 indicates the strong relationship between these two factors. For example between 2005 and 2009 the total increase of AADE was $21.9 \%$ while incidents were increased by $17.2 \%$.

In 2010 the reduction of AADE was $8.5 \%$ and has almost the same effect on the reduction in the number of incidents which was $8.4 \%$. This significant association does not seem to be valid for 2011

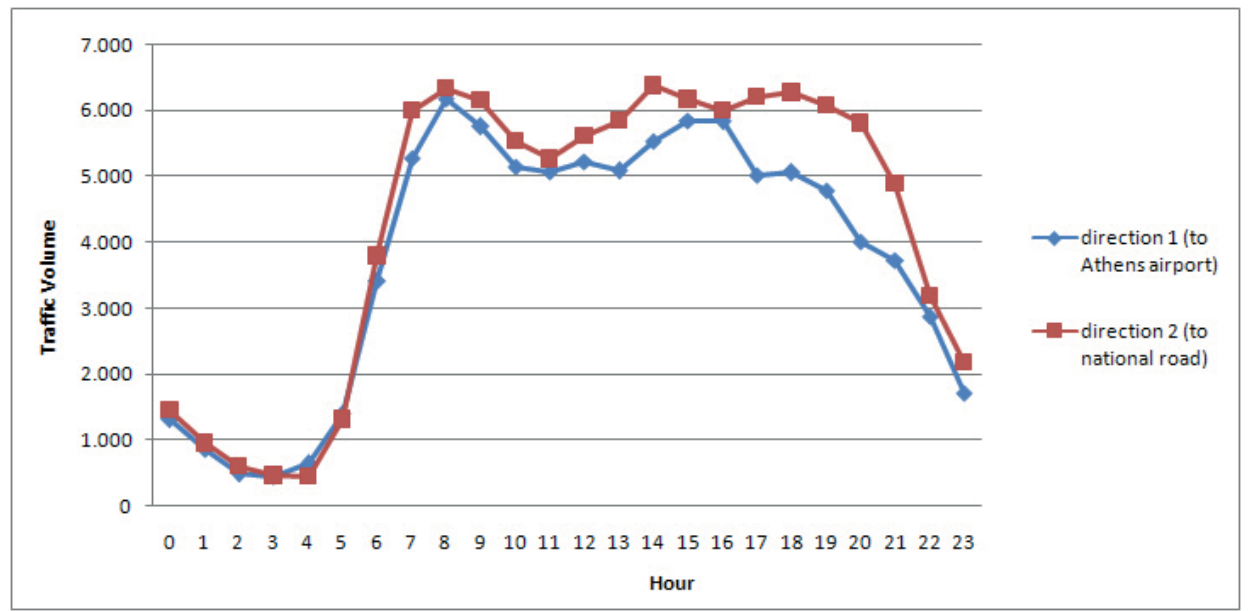

Figure 5: Typical hourly volume distribution in central, $10 \mathrm{~km}$ urban section in AT (Working day, 2009). 


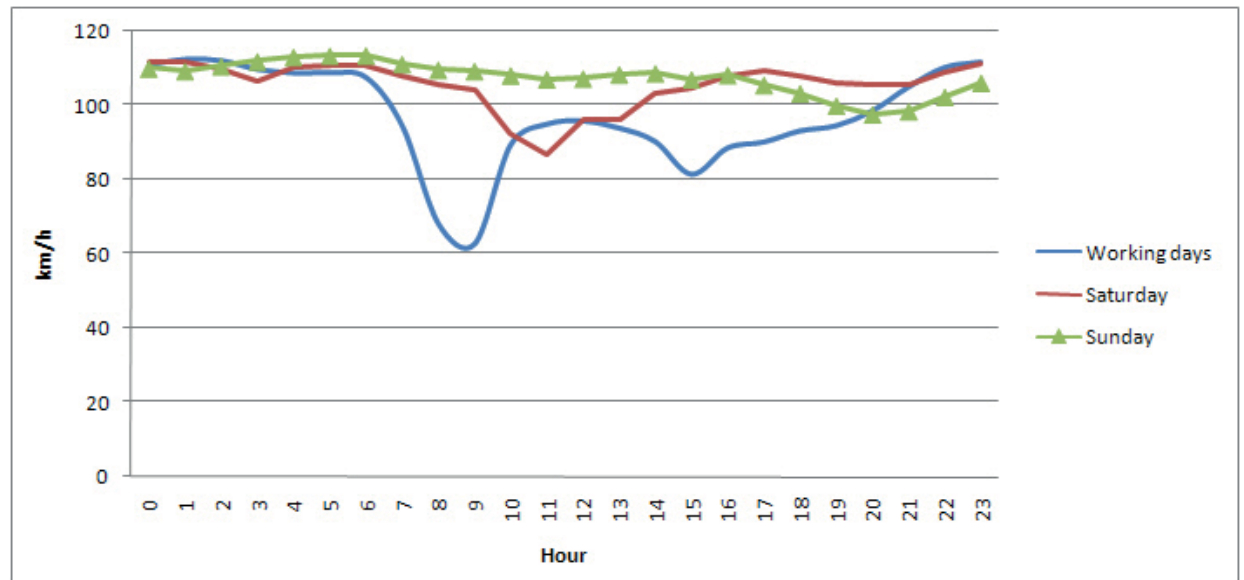

Figure 6: Average hourly distribution of speed in $10 \mathrm{~km}$ central urban section in AT (July 2009).

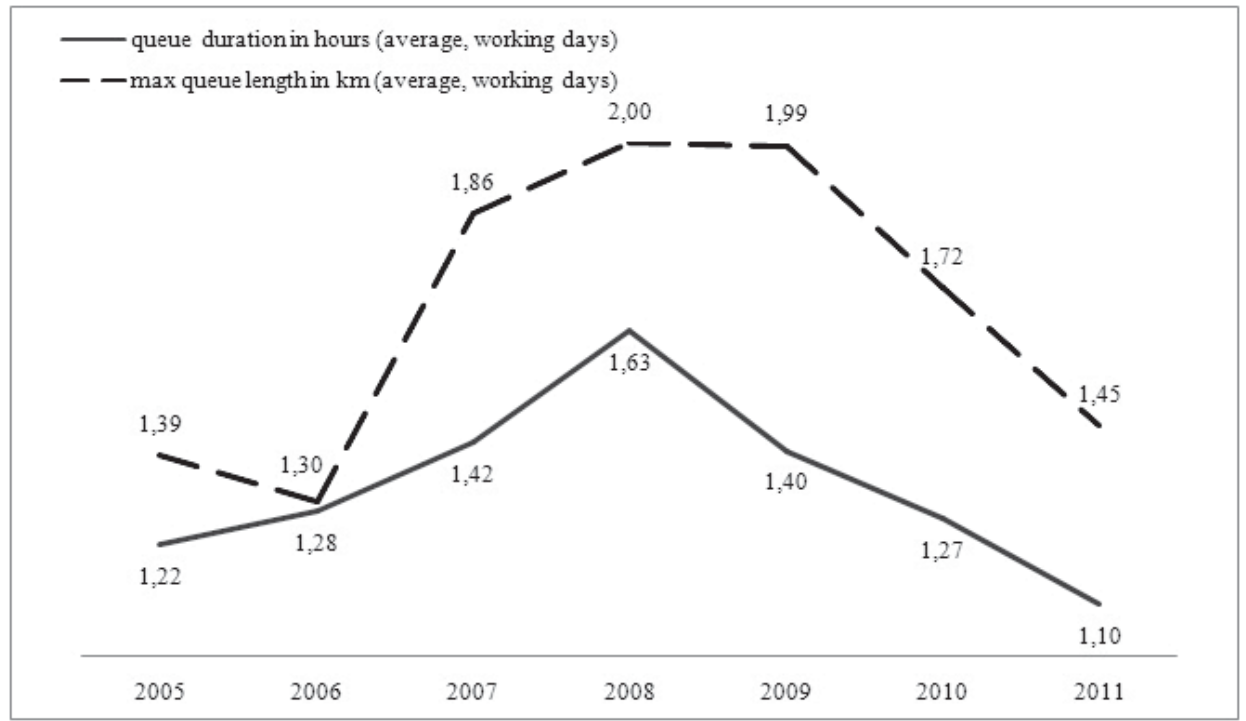

Figure 7: Average queue duration and length in AT (2005-2011).

when a reduction in AADE was $11 \%$ and has practically no result on incident occurrences $(-1.5 \%)$ due to increase of other types of incidents like vehicle breakdown, obstacles, etc.

According to the total number of incidents, recurrent and non recurrent, congestions were 684 or 2 per day in 2005 and 2007 or 5 per day in 2008. A definition of congestion involves elevated density (detector occupancy above $30 \%$ ) and low speed, usually under $30 \mathrm{mph}$, although speeds in the range between 40 and $60 \mathrm{mph}$ are indicative of congestion, if speed downstream the bottleneck is clearly above $60 \mathrm{mph}$ and detector occupancy is at or below $10 \%$.

Congestion is also characterized by the formation of queues which must also be sustained for a minimum period (e.g., 30 minutes or more) and in the long term; for example, Chen et al. [15] used a criterion for bottleneck presence based on $90 \%$ of days analyzed for a minimum of three months of data. 
Table 1: Traffic, incidents and congestions in AT (2005-2011).

\begin{tabular}{lccccccc}
\hline & $\mathbf{2 0 0 5}$ & $\mathbf{2 0 0 6}$ & $\mathbf{2 0 0 7}$ & $\mathbf{2 0 0 8}$ & $\mathbf{2 0 0 9}$ & $\mathbf{2 0 1 0}$ & $\mathbf{2 0 1 1}$ \\
\hline $\begin{array}{l}\text { Annual Average Daily Entries } \\
\text { (AADE) }\end{array}$ & $\mathbf{2 4 8 7 8 4}$ & $\mathbf{2 7 0 0 0 2}$ & $\mathbf{2 9 5 1 4 0}$ & $\mathbf{3 0 0 9 9 3}$ & $\mathbf{3 0 7 3 0 0}$ & $\mathbf{2 8 1 3 2 4}$ & $\mathbf{2 5 0 4 9 1}$ \\
$\begin{array}{l}\text { (\%) compared to previous year } \\
\text { Incidents }\end{array}$ & - & $8,5 \%$ & $9,3 \%$ & $2,0 \%$ & $2,1 \%$ & $-8,5 \%$ & $-11,0 \%$ \\
$\begin{array}{l}\text { (\%) compared to previous year } \\
\text { Congestions }\end{array}$ & - & $8,5 \%$ & $9,2 \%$ & $0,8 \%$ & $-1,2 \%$ & $-8,4 \%$ & $-1,5 \%$ \\
$\quad \begin{array}{l}\text { Due to incidents/accidents } \\
\quad \text { Due to traffic demand }\end{array}$ & 94 & 138 & 206 & 183 & 188 & 192 & 99 \\
$\quad$\begin{tabular}{l} 
Total Congestions \\
\hline
\end{tabular} & 590 & 958 & 1608 & 1894 & 1706 & 968 & 571 \\
& $\mathbf{6 8 4}$ & $\mathbf{1 0 9 6}$ & $\mathbf{1 8 1 4}$ & $\mathbf{2 0 7 7}$ & $\mathbf{1 8 9 4}$ & $\mathbf{1 1 6 0}$ & $\mathbf{6 7 0}$ \\
\hline
\end{tabular}

For year 2010 and 2011 a significant reduction in congestion appears (Fig.7). Congestion average duration was the maximum in 2008 (1.63 hours) and the minimum in 2011 (1.1 hour). Also the average maximum in length had the highest value in years 2008 and 2009 (about $2 \mathrm{~km}$ ).

The Attica Tollway Patrol Service (ATPS) consists of personnel of 55 Patrols who are using a fleet of 20 small trucks fully equipped with road signs, cones, traffic lights and other emergency equipment.

Patrols are supervised and guided 24/7 by the Traffic Management Centre (TMC) of the Attica Tollway. In an average day ATPS intervenes in 72 incidents in 2011 when 26.290 was the total of incidents recorded.

The average duration was 16 minutes per assistance. Out of the total number, $75 \%$ of the incidents were vehicle breakdowns and $20 \%$ of the incidents had as result one or more lane closure. The average response time, i.e. the time between the first notification to a Patrol by TMC operators and first arrival at the site of the incident, was 5.9 minutes for 2011. Traffic Police and Fire Brigade response time was 12 and 11 minutes respectively.

\section{THE FREEWAY SERVICE PATROL EVALUATION (FSPE) MODEL}

The FSPE model was developed in California, USA by the University of Berkeley on behalf of California Department of Transportation (Caltrans). Evaluation takes place in 2 stages $[16,17]$ as follows:

a. Calculation of delays, fuel consumption and emissions saved by events treated "with" Patrol Service in comparison with those that treated "without" Patrol Service.

b. Estimation of the benefit/cost ratio of Patrol Service with quantification of the benefits and cost. Cost is consisted of operating and administrative cost of patrol Service.

For calculating delays produced by incidents, FSPE uses deterministic models of queue theory. As well as data, as follows:

i. Geometric characteristics of the freeway

ii. Traffic Data per hour

iii. Incidents details (type, lane affected, duration, etc)

iv. Response times of Patrol Service as the main and critical parameter of the queue due to incident (the sooner it arrives the soonest the road is cleared)

v. Average Occupancy per car-trip, value of time per passenger-hour 
vi. Road capacity reduction factors in condition of incident

vii. Patrol Service (overhead cost) operational elements and costs (employees, salary, working hours, vehicle costs, etc)

An analyzed description and data used for the evaluation of ATPS through FSPE is given by Kopelias et al. [18].

\section{FUEL CONSUMPTION AND POLLUTANTS EMISSION FACTORS}

FSPE model calculates the amount of emitted pollutants (CO, NOx, etc.) savings due to congestion and queue reduction in case of Patrol intervention. The methodology for calculating emissions is based on the EMFAC model [19] (EMission FACtors) which is used to estimate emissions for all types of vehicles (cars, heavy, buses etc) and all types of networks in California, United States. This model is used also by California Air Resources Board - CARB. Because of the difference in vehicle types in Greece (smaller cars, small engine capacity, road network, etc) an adjustment of emission factors is necessary to be made.

The European Environment Agency in its latest version [19] of the air pollution from road transport directive (European Environment Agency, 2009) proposed emission rates based on European standards since the 90's (Euro 1) up to 2005 and beyond (Euro 4). These guidelines cover the majority of vehicles in the European Union while the two subsequent standards (Euro 5 and Euro 6) started in 2009. To calculate pollutants based on European specifications, in AT, the following assumptions are considered:

a. The entire fleet is specified by the standard EURO 3 (2000 and beyond)

b. The classification of vehicles, assumes that $95 \%$ are gasoline passenger cars and 5\%are diesel trucks

c. Passenger cars have an average of $1400 \mathrm{cc}$ engine

d. Trucks have an average weight of $12-14 t$ with $50 \%$ load

\subsection{Passenger cars}

Hot emissions estimates for Euro 2 and post-Euro 1 gasoline passenger cars are calculated as a function of speed. They have been developed in the framework of the Artemis Project [20]. The generic function used in this case is:

$$
E F=\left(a+c \times V+e \times V^{2}\right) /\left(1+b \times V+d \times V^{2}\right)
$$

where:

$E F$ (Emission Factor): emissions and fuel consumption in $\mathrm{g} / \mathrm{km}$

$V$ :

speed in $\mathrm{km} / \mathrm{h}$

$a, b, c, d, e: \quad$ model parameters, given in Tables 2 and 3 .

For the specific purpose it is assumed that AT has $15 \%$ urban characteristics and $85 \%$ highway characteristics.

\subsection{Trucks}

Speed dependencies of emission factors for diesel heavy duty vehicles have been built on the results provided by the Artemis Project. Similarly, the methodology provides hot emission factors for urban busses and coaches. The emission factors are provided for conventional, Euro I to Euro V standards. 
Table 2: Values of model parameters for eqns (1) to (6) to calculate emissions and fuel consumption.

\begin{tabular}{|c|c|c|c|c|c|c|c|}
\hline & $\begin{array}{c}\text { Air } \\
\text { Pollutant }\end{array}$ & $\begin{array}{c}\text { Speed Range } \\
(\mathrm{km} / \mathbf{h})\end{array}$ & a & b & c & d & e \\
\hline \multirow{4}{*}{$\begin{array}{l}\text { Passenger Cars } \\
\text { EURO3 - } 1,4 \mathrm{cc}\end{array}$} & $\mathrm{CO}$ & $10-130$ & $7.17 \mathrm{E}+01$ & $3.54 \mathrm{E}+01$ & $1.14 \mathrm{E}+01$ & $-2.48 \mathrm{E}-01$ & - \\
\hline & $\mathrm{HC}$ & $10-130$ & $5.57 \mathrm{E}-02$ & $3.65 \mathrm{E}-02$ & $-1.10 \mathrm{E}-03$ & $-1.88 \mathrm{E}-04$ & $1.25 \mathrm{E}-05$ \\
\hline & NOx & $10-130$ & $9.29 \mathrm{E}-02$ & $-1.22 \mathrm{E}-02$ & $-1.49 \mathrm{E}-03$ & $3.97 \mathrm{E}-05$ & $6.53 \mathrm{E}-06$ \\
\hline & $\mathrm{FC}^{*}$ & $10-130$ & $1.94 \mathrm{E}+02$ & $9.44 \mathrm{E}-02$ & $3.36 \mathrm{E}-01$ & $-4.37 \mathrm{E}-04$ & $7.32 \mathrm{E}-03$ \\
\hline \multirow{5}{*}{$\begin{array}{l}\text { Trucks - EURO3, } \\
12-14 \text { t, } 0 \% \text { gradient, } \\
50 \% \text { load factor }\end{array}$} & $\mathrm{CO}$ & $6-86$ & $3,67 \mathrm{E}+00$ & $5,64 \mathrm{E}-02$ & $5,23 \mathrm{E}+00$ & $2,29 \mathrm{E}-01$ & $7,32 \mathrm{E}-01$ \\
\hline & $\mathrm{HC}$ & $6-86$ & $8,37 \mathrm{E}-02$ & $1,32 \mathrm{E}+00$ & $4,53 \mathrm{E}+00$ & $1,89 \mathrm{E}+00$ & $-1,04 \mathrm{E}-02$ \\
\hline & NOx & $6-86$ & $8,84 \mathrm{E}+00$ & $5,82 \mathrm{E}-02$ & $3,28 \mathrm{E}+01$ & $3,25 \mathrm{E}-01$ & $3,76 \mathrm{E}+00$ \\
\hline & $\mathrm{PM}$ & $6-86$ & $7,53 \mathrm{E}-03$ & $4,82 \mathrm{E}-01$ & $4,58 \mathrm{E}+00$ & $1,88 \mathrm{E}+00$ & $-2,24 \mathrm{E}-02$ \\
\hline & $\mathrm{FC}^{*}$ & $6-86$ & $1,47 \mathrm{E}-03$ & $1,64 \mathrm{E}-04$ & $-1,25 \mathrm{E}-06$ & & \\
\hline
\end{tabular}

*Fuel Consumption.

Source: [21].

Table 3: PM emission factors for Euro 3 and later gasoline passenger cars.

\begin{tabular}{llllll}
\hline Pollutant & $\begin{array}{l}\text { Emission } \\
\text { standard }\end{array}$ & $\begin{array}{l}\text { Fuel specs } \\
(\text { EN590) }\end{array}$ & Urban [g/km] & Rural [g/km] & $\begin{array}{l}\text { Highway } \\
{[\mathbf{g} / \mathbf{k m}]}\end{array}$ \\
\hline PM & Euro 3 and 4 & $2000-2009$ & $1.28 \mathrm{E}-03$ & $8.36 \mathrm{E}-04$ & $1.19 \mathrm{E}-03$ \\
\hline
\end{tabular}

Source: [21].

The emissions covered by the methodology are $\mathrm{CO}, \mathrm{VOC}, \mathrm{NO}_{\mathrm{X}}, \mathrm{PM}$ and Fuel Consumption (FC). Ten main equations are used to calculate the emission factors, while the relevant EMEP/EEA 2009Annex3 [21] contains the necessary parameters in a specific structure.

For the specific purpose and the assumptions described above, fuel consumption and pollutants emissions are given by the following eqns (2) to (6):

Fuel Consumption $(\mathrm{g} / \mathrm{km})$ :

$$
F C=1 /\left(c \times V^{2}+b \times V+a\right)
$$

Emissions $(\mathrm{g} / \mathrm{km})$ :

$$
\begin{gathered}
C O=e+a \times \exp ^{(-1 \times b \times V)}+c \times \exp ^{(-1 \times d \times V)} \\
H C=a+b /\left(1+\exp ^{(-1 \times c+d \times \ln V)}+e \times V\right) \\
N O x=e+a \times \exp ^{(-1 \times b \times V)}+c \times \exp ^{(-1 \times d \times V)} \\
P M=a+b /\left(1+\exp ^{(-1 \times c+d \times \ln V)}+e \times V\right)
\end{gathered}
$$

where:

$V: \quad$ speed in $\mathrm{km} / \mathrm{h}$

$a, b, c, d, e$ : variables, given in Table 2 hereafter. 
6 FSPE, FUEL CONSUMPTION AND EMISSION SAVINGS RESULTS

Using the assumptions and functions introduced before, emission rates have been calculated and entered in FSPE model in sheet PARAMS [17] for different level of speed. Figures 8 and 9 illustrate the fuel consumption and emissions "profile" of the all AT traffic (cars and trucks).

FSPE model has been examined for the effect of ATSP in the total length of the freeway for a whole year. The relevant results (see Table 4), are referred to traffic volumes, incidents features, operational elements and cost for 2009 (which refers to the year with the highest traffic demand and with the maximum -up to now -company workforce i.e. patrol employees, fleet, etc).

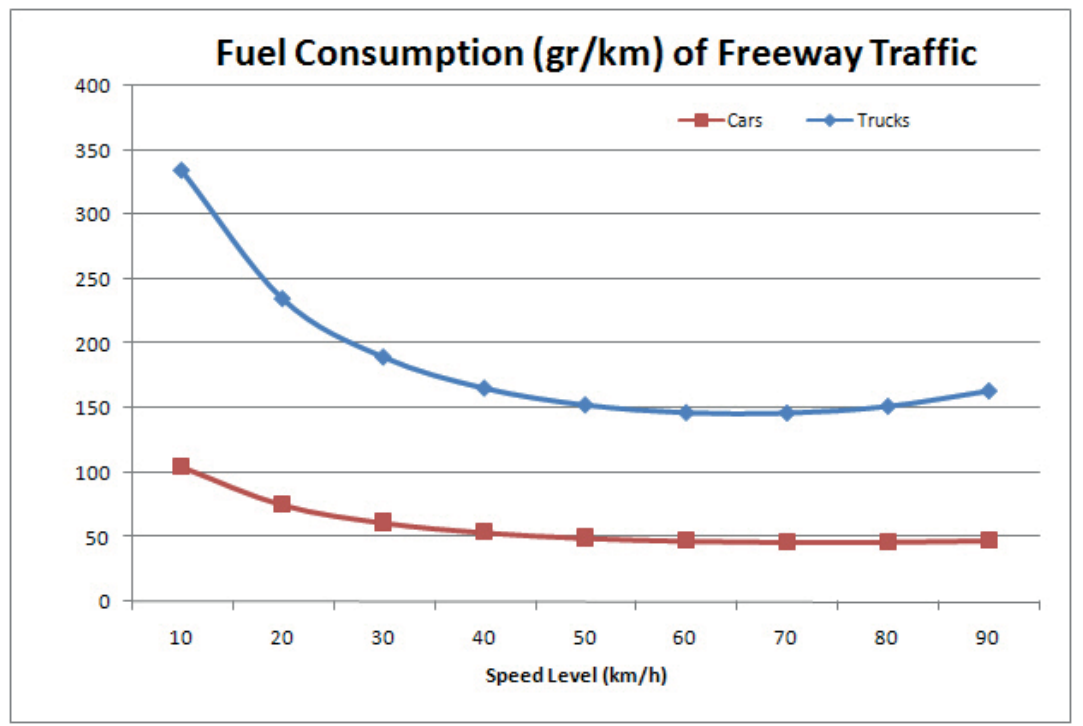

Figure 8: Fuel consumption per speed for AT traffic.

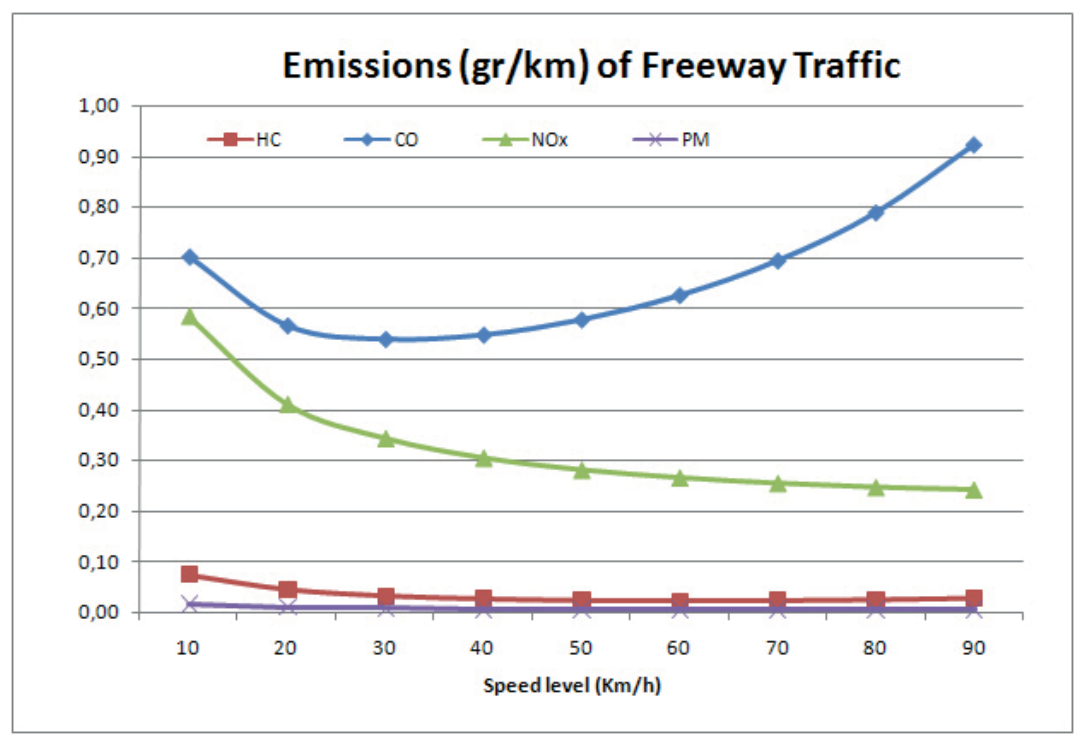

Figure 9: Emission per speed for AT traffic. 
Table 4: Results of FSPE model (2009).

\begin{tabular}{ll}
\hline Emission reduction (kg/year) & \\
$\mathrm{HC}$ & 725 \\
$\mathrm{CO}$ & 15.477 \\
$\mathrm{NO}_{\mathrm{X}}$ & 8.548 \\
$\mathrm{PM}$ & 152.3 \\
Fuel Consumption reduction (mil.lit/year) & 2,4 \\
Benefit from fuel consumption reduction (mil.€/year)* & 3,3 \\
Delays reduction (vehicle hours) & 701.969 \\
Benefit of delays reduction (mil.€/year) & 9,3 \\
Total Benefit (mil.€/year) & 12,6 \\
Cost of TSP (mil.€/year) & 2,9 \\
B/C ratio & $\mathbf{4 , 3 : 1}$ \\
\hline
\end{tabular}

*av.price per lit in 2010 .

\section{CONCLUSIONS}

The new fully operating updated network of Attica Tollway (AT) ensures, the continuous recording of $\mathrm{CO}, \mathrm{NO}_{2}, \mathrm{PM}_{10}, \mathrm{PM}_{2.5}$ \& $\mathrm{BTEX}$ as well as the continuous recording and monitoring of the Road Traffic Noise indices as per the EU directive 2002/49/EC and the relative existing Greek legal framework, within a full communication telematics network based on optical fibres.

The monitored environmental data indicates a strong and direct relationship between air pollutant emissions and traffic flows in the Attica Tollway network, representing a $70 \mathrm{~km}$ ring road of Athens.

Traffic incident management is the main action which is used by AT operator agency in order to minimize the impact of traffic incidents and non-recurrent congestion. According to the total number of incidents, recurrent and non recurrent, congestions were 2 per day in 2005 and 2007 or 5 per day in 2008 .

A definition of congestion involves elevated density (detector occupancy above 30\%) and low speed, usually under $30 \mathrm{mph}$, although speeds in the range between 40 and $60 \mathrm{mph}$ are also indicative of congestion, if speed downstream the bottleneck is clearly above $60 \mathrm{mph}$ and detector occupancy is at or below 10\%. However for year 2010 and 2011 a significant reduction was monitored.

In this article and in order to further calculate and evaluate the benefits of AT incident management which is given through Attica Tollway Patrol Service (ATPS), the Freeway Service Patrol Evaluation Methodology (FSPE) was used to calculate the savings in fuel consumptions, emissions and delays of the operation of Attica Tollway Patrol Service.

The FSPE model evaluation considers the benefit resulting from the reduction of delays, fuel consumption and emissions comparing "with" and "without" ATPS features and effects of an incident (duration, lane/s closure, capacity reduction, delays, average speed in queue, etc).

The relevant results show that:

a. $\mathrm{B} / \mathrm{C}$ ratio is greater than 1 indicating that ATPS present more benefits than costs. The ratio is 4.3:1 i.e. the annual cost of about 3 million for the Patrol Service, returns over 4 times more benefits from delays and fuel consumption reduction.

b. ATSP contributes savings of 701,969 vehicle hours per year which costs about 9.3 million euro to the road users. It also contributes in saving 2.401.640 litres of fuel or 3.3 million euro 
(av. price 2010 in Greece). The total economic benefit for the road users reaches the value of 12.6 million euro in one year.

c. Reduction of queues and speed reduction in conditions of congestion has a remarkable effect on environmental conditions as well. FSPE model was adapted to Greek - European emission factors and the output is a reduction in emissions by $15.477 \mathrm{~kg} /$ year of $\mathrm{CO}, 8.548 \mathrm{Kg}$ / year of $\mathrm{NO}_{\mathrm{X}}$ and $725 \mathrm{~kg} / \mathrm{year}$ of $\mathrm{HC}$.

\section{REFERENCES}

[1] Federal Highway Administration, Traffic Congestion and Reliability: Linking Solutions to Problems, Final Report, prepared by Cambridge Systematics \& Texas Transportation Institute: Washington DC, 2004.

[2] Federal Highway Administration, Traffic Incident Management Handbook, US DOT, Office of Travel Management: Washington DC, 2003.

[3] Texas Transportation Institute, Urban Mobility Report, 2003.

[4] National Traffic Incident Management Coalition National Unified Goal, available at http:// timcoalition.org/?siteid=41\&pageid=, 1973.

[5] Texas Transportation Institute, Urban Mobility Report, 2011.

[6] Salimol, T. \& Jacko, R.B., A stochastic model for estimating the Impact of highway incidents on air pollution and traffic delay. Transportation Research Record: Journal of the Transportation Research Board, No. 2011, eds. T. Salimol \& J. Robert, Transportation Research Board of the National Academies: Washington, DC, pp. 107-115, 2007.

[7] Federal Highway Administration, Service Patrol Handbook, US DOT Report FHWAHOP-08-031: Washington DC, 2008.

[8] U.S. Department of Transportation Federal Highway Administration, Best Practices in Traffic Incident Management, Report FHWA-HOP-10-050, 2010.

[9] Basbas, S., Pitsiava-Latinopoulou, M. \& Zacharaki, E., Motorized road transport: economic and environmental costs - A policy assessment framework. International Journal of Sustainable Development and Planning, 4(4), pp. 309-321, 2009. doi: http://dx.doi.org/10.2495/SDPV4-N4-309-321

[10] Giuffre, O., Grana, A., Giuffre, T. \& Marino, M. Emission factors related to vehicle modal activity. International Journal of Sustainable Development and Planning, 6(4), pp. 447-458, 2011. doi: http://dx.doi.org/10.2495/SDP-V6-N4-447-458

[11] Vogiatzis, K., Halkias, V. \& Mandalozis, D., The new integrated monitoring system of environmental road noise and air pollution of Attiki Odos motorway according to the EU directives 2008/50/EU \& 2002/49/EU, 5th International Congress for Transport Research: Energy, environment and transport, Volos, Greece, 27-28.09. 2010.

[12] DIRECTIVE 2008/50/EC of the EUROPEAN PARLIAMENT and of the COUNCIL of 21 May 2008 on ambient air quality and cleaner air for Europe, Official Journal of the European Union L 152/1 11.6.2008.

[13] JMD 13586/724/FEK/B/384/28/3/2006 regarding the adaptation of the Greek legal framework to the European Directive 2002/49/EC of the EUROPEAN PARLIAMENT and of the COUNCIL of 25 June 2002 relating to the assessment and management of environmental noise, Official Journal of the European Communities L 189/1218.7.2002.

[14] Transportation Research Board, Highway Capacity Manual, Washington, DC, USA, 2010.

[15] Chen, C., Skabardonis, A. \& Varaiya, P., Systematic Identification of Freeway Bottlenecks Transportation Research Record: Journal of the Transportation Research Board, No. 1867, TRB, National Research Council, Washington, DC, pp. 46-52, 2004. 
[16] Skabardonis, A., FSP Beat Evaluation Routine, Technical Report, prepared for Caltrans Office of Traffic Operations: UC Berkeley, 2000.

[17] Skabardonis A. \& Mauch, M., FSP Beat Evaluation and Predictor Models: Users Manual, Research Report UCB-ITS-RR-2005-XX: UC Berkeley, 2005.

[18] Kopelias, P., Skabardonis, A., Fanis Papadimitriou, F. \& Hrisikakis, P., MBA Improving traffic flow and environment through freeway service patrol. An evaluation study, 5th International Congress for Transport Research Volos, Greece, 27-28.09.2010.

[19] Emission Factor Model, EMFAC 2007, available at http://www.arb.ca.gov/msei/onroad/latest_ version.htm

[20] ARTEMIS Assessment and Reliability of Transport Emission Models and Inventory Systems, Research Project funded by the European Commission - Directorate General Transport and Energy, 2006.

[21] Ntziachristos, L. \& Samaras, Z., EMEP/EEA air pollutant emission inventory guidebook - 2009: Exhaust emissions from road transport (Categories A.3.b.i, 1.A.3.b.ii, 1.A.3.b.iii, 1.A.3.b.iv : Passenger cars, light-duty trucks, heavy-duty vehicles including buses and motor cycles) Technical report No 9/2009 updated June 2010. 